\title{
Application of copper sulfate based fenton-like catalyst in degradation of quinoline
}

\author{
Zhaojie Jiao ${ }^{1}$, Haifeng Gong ${ }^{1}$, Ye Peng ${ }^{1}$, Guilin Zhou ${ }^{1}$, Xianming Zhang ${ }^{1^{\dagger}}$, Xu Gao ${ }^{1}$, Yunqi Liu $^{2}$ \\ ${ }^{1}$ Engineering Research Center for Waste Oil Recovery Technology and Equipment, Ministry of Education, Chongqing Technology and Business \\ University, Chongqing 400067, China \\ ${ }^{2}$ State Key Laboratory of Heavy Oil Processing, China University of Petroleum (East China), Qingdao 266580, China
}

\begin{abstract}
In the practical application of water treatment, the Fenton reaction usually works at a lower $\mathrm{pH}$. To overcome the above shortcomings, a Fenton-like reaction system with copper sulfate as a catalyst was proposed. In this paper, quinoline was used as the target pollutant and the effects of catalyst dosage, $\mathrm{H}_{2} \mathrm{O}_{2}$ dosage, reaction temperature, and initial concentration of quinoline and $\mathrm{pH}$ on the removal effect were investigated, and the evolution in $\mathrm{pH}$ and hydroxyl radical concentration during reaction, as well as the possible catalytic mechanism and degradation pathway were clarified. The results show that under a catalyst dosage of $0.4 \mathrm{~g} \cdot \mathrm{L}^{-1}$, a $\mathrm{H}_{2} \mathrm{O}_{2}$ dosage of $196 \mathrm{mmol} \cdot \mathrm{L}^{-1}$, a quinoline concentration of 100 $\mathrm{mg} \cdot \mathrm{L}^{-1}$ and a temperature of $75^{\circ} \mathrm{C}$, the removal of quinoline and total organic carbon (TOC) reaches $99.5 \%$ and $87.2 \%$ in 65 min, respectively. Furthermore, the copper sulfate-driven homogeneous Fenton system exhibits a superior adaptability to $\mathrm{pH}$ in the range of 3.8 to 8.8 . In the degradation of quinoline, $\cdot \mathrm{OH}$ radicals may attack the nitrogen ring and the benzene ring in sequence. The work provides a technical support for the treatment of organic wastewater, and shows promising in practical applications.
\end{abstract}

Keywords: Copper sulfate, Degradation, Fenton-like, Hydroxyl radical, Quinolone

\section{Introduction}

With the rapid development of economy, the industrial products and by-products generated during human activities, especially in production of chemical, pharmaceutical, printing and dyeing and petrochemical industries, have been released into the natural water without treatment. Organic compounds in those industrial products and by-products are often toxic and difficult to biodegrade [1, 2]. Quinoline is such the compound and it is a typical nitrogen heterocyclic compound mainly resulting from coking, dye, oil refining and pharmaceutical wastewater [3, 4]. As a water-soluble and volatile compound [5], it often exists in soil, groundwater and air [4, 6] and, its concentration in coking wastewater is very high up to $86.8 \mathrm{mg} \cdot \mathrm{L}^{-1}$ [7]. It has a relatively stable loop structure, thus it is difficult to biodegrade. Also, it is easy to cause an acidification and eutrophication of water [8]. Furthermore, its toxicity [9] includes causing cancer, teratogenesis and mutagenicity of animals and human $[8,10]$. Overall, it has posed a threat to water ecological security and human health. Therefore, developing economical and efficient method for the remediation of quinoline wastewater pollution is needed.

The common method for the degradation of the quinoline includes physical, biological and advanced oxidation methods. The degradation of organic matter into small molecular compounds by traditional physical methods such as membrane technology, ion exchange and activated carbon adsorption [11, 12], is not able to achieve. The drawbacks for the biological method are that: the quinoline has an inhibiting effect on the microorganisms so that the structure of quinoline cannot be recognized by enzyme system of the microorganisms, thus we have to carry out a screen of special strains $[13,14]$. Also, sludge acclimatization is time-consumption [15] and its degradation treatment is often conduced on a large-scale which is high cost [16]. Furthermore, some of organics are degraded into intermediates and they would be not easily accumulated [17].

Fortunately, advanced oxidation technologies, such as supercritical water oxidation [18, 19], ozone oxidation [6], ultraviolet radiation [20], photocatalytic oxidation [21, 22], electrocatalytic oxidation [10, 23] and wet oxidation [8, 24], have been applied
This is an Open Access article distributed under the terms of the Creative Commons Attribution Non-Commercial License (http://creativecommons.org/licenses/by-nc/3.0/) which permits unrestricted non-commercial use, distribution, and reproduction in any medium, provided the original work is properly cited.

Copyright (C) 2022 Korean Society of Environmental Engineers
Received June 30, 2021 Accepted September 20, 2021

${ }^{\dagger}$ Corresponding author

E-mail: zxm215@126.com

Tel: +86-23-62768317

ORCID: 0000-0003-2670-4957 
to degradation of resistant organic wastewater by generating oxidative free radicals. But, photocatalytic oxidation has an inferior effect on treatment of wastewater containing poor light transmission; supercritical oxidation has a high requirement for reaction equipment; electrocatalysis and ultrasonic oxidation are only effective in laboratory at present; the wet oxidation and catalytic wet oxidation need to conduct under high temperature and high pressure [25]. For example, Nilam J [8] showed that using $\mathrm{Ru} / \mathrm{C}$ catalyst to remove quinoline needed to complete under a temperature up to $493 \mathrm{~K}$ and oxygen partial pressure up to $0.69 \mathrm{MPa}$. Although catalytic wet peroxide oxidation has a strong oxidation capacity, high mineralization efficiency and fast reaction rate for quinoline, some existing problems such as complex catalyst preparation, high cost and easy precipitation of active components [26, 27] are not avoided. Fenton method is the cost-effective advanced oxidation technology which has been widely applied in water treatment. However, its solution is often yellowish resulting in from ion element and effective treatment often reaches under low $\mathrm{pH}$ around 2 to 4 [28], and finally numerous iron-containing sludge needs to further treat [29]. Therefore, it is a challenge to improve $\mathrm{pH}$ effect and obtain a cost-effective method for treatment of polluted water.

In this study, the degradation effect of quinoline by hydrogen peroxide catalyzed by copper sulfate was investigated, which was a new Fenton-like system. In the system, effect of the parameters affecting the catalysis effect of copper ion on hydrogen peroxide, such as dosage of copper sulfate as catalyst, $\mathrm{H}_{2} \mathrm{O}_{2}$ dosage, reaction temperature, initial concentration and $\mathrm{pH}$, was investigated by measuring the removal of quinoline. Possible degradation paths and the catalytic mechanism were analyzed.

\section{Materials and Methods}

\subsection{Materials and Instruments}

All chemicals used in this study were of analytical reagent grade. The chemicals such as quinoline $\left(\mathrm{C}_{9} \mathrm{H}_{7} \mathrm{~N}\right.$, Adamas Reagent Co.,Ltd), coumarin $\left(\mathrm{C}_{9} \mathrm{H}_{6} \mathrm{O}_{2}\right.$, Adamas Reagent Co.,Ltd), 7-hydroxyl coumarin $\left(\mathrm{C}_{9} \mathrm{H}_{6} \mathrm{O}_{3}\right.$, Acros $)$, copper chloride $\left(\mathrm{CuCl}_{2} \cdot 2 \mathrm{H}_{2} \mathrm{O}\right.$, Guangdong Chemical Reagent Engineering Research and Development Center), copper acetate $\left(\mathrm{C}_{4} \mathrm{H}_{6} \mathrm{CuO}_{4} \cdot \mathrm{H}_{2} \mathrm{O}\right.$, Tianjin Regent Chemicals Co.,Ltd), Ferrous sulfate, $\left(\mathrm{FeSO}_{4} \cdot 7 \mathrm{H}_{2} \mathrm{O}\right)$, ferric sulfate $\left(\mathrm{Fe}_{2}\left(\mathrm{SO}_{4}\right)_{3}\right)$, manganese sulfate $\left(\mathrm{MnSO}_{4} \cdot \mathrm{H}_{2} \mathrm{O}\right)$, were purchased from Chengdu Cologne Chemical Co., Ltd.. Other chemicals (such as nitric acid copper $\left(\mathrm{Cu}\left(\mathrm{NO}_{3}\right)_{2} \cdot 3 \mathrm{H}_{2} \mathrm{O}\right)$, copper sulfate $\left(\mathrm{CuSO}_{4} \cdot 5 \mathrm{H}_{2} \mathrm{O}\right)$, titanium dioxide $\left(\mathrm{TiO}_{2}\right)$ ) were purchased from Chengdu Kelon Chemical Reagent Factory, hydrogen peroxide $\left(\mathrm{H}_{2} \mathrm{O}_{2}, 30 \%\right)$, and those such as (hydrochloric acid ( $\mathrm{HCl}$ ), sulfuric acid $\left(\mathrm{H}_{2} \mathrm{SO}_{4}\right)$, sodium hydroxide $(\mathrm{NaOH})$ ) were purchased from Chongqing Chuandong Chemical (group) Co., Ltd..

\subsection{Experimental}

Experiment of degradation of quinoline wastewater by the Fenton-like catalytic oxidation was carried out in a corked conical flask within a thermostatic water bath. A fixed concentration of simulated quinoline solution $\left(7.2-100 \mathrm{mg} \cdot \mathrm{L}^{-1}, \mathrm{pH}\right.$ 3.8-8.8) was prepared by adding quinoline and distilled water in a conical flask, following by a certain amount of catalyst copper sulfate (0.2-1.28 $\mathrm{g} \cdot \mathrm{L}^{-1}$,) and a certain amount of $\mathrm{H}_{2} \mathrm{O}_{2}\left(\mathrm{~m} / \mathrm{m}, 30 \%\right.$, 78-470 $\left.\mathrm{mmol} \cdot \mathrm{L}^{-1}\right)$. Subsequently, the solution reacted for a certain time at a stirring speed of $120 \mathrm{rpm} / \mathrm{min}$ and a certain temperature $\left(55-85^{\circ} \mathrm{C}\right)$. Then, the samples were centrifuged and the supernatant was collected for measurement of total organic carbon (TOC) and UV-Vis absorbance, respectively.

\subsection{Analytical Methods}

The UV-vis adsorption spectroscopy (UV-2550, Japan Shimadzu) of quinoline was measured, as shown in Fig. 1(a). A standard curve of the concentration of quinoline vs. absorbance at $312.4 \mathrm{~nm}$ of quinoline was created. The unknown quinoline concentration of samples through the absorbance and the curve was determined. TOC of samples was determined by total organic carbon (TOC) analyzer (TOC-VCPN, Japan Shimadzu). The concentration of $\mathrm{H}_{2} \mathrm{O}_{2}$ was calculated by titanium spectrophotometry method [30]. As reported in previous research [31], the concentration of hydroxyl radical $(\bullet \mathrm{OH})$ was determined by coumarin using a fluorescence spectrophotometer ((F-7100, Japan HITACHI)). Fluorescence scanning of coumarin and 7-hydroxycoumarin is shown in Fig. 1(b)-(c). The maximum excitation wavelength/ emission wavelength of coumarin was at 277/392 $\mathrm{nm}$ (see Fig. 1(b)), the maximum excitation wavelength/emission wavelength of 7-hydroxycoumarin was at 321/452.6 nm (Fig. 1(c)). Degradation products were analyzed using gas chromatography-mass spectrometry (GC-MS, 7890b/5977b,

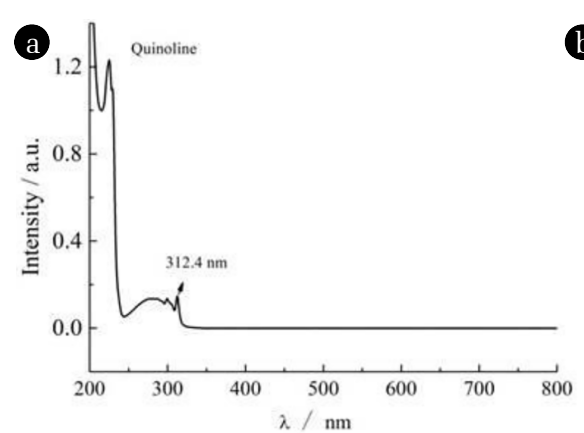

Fig. 1. (a) UV-vis adsorption spectroscopy of quinoline, 7-Hydroxycoumarin.
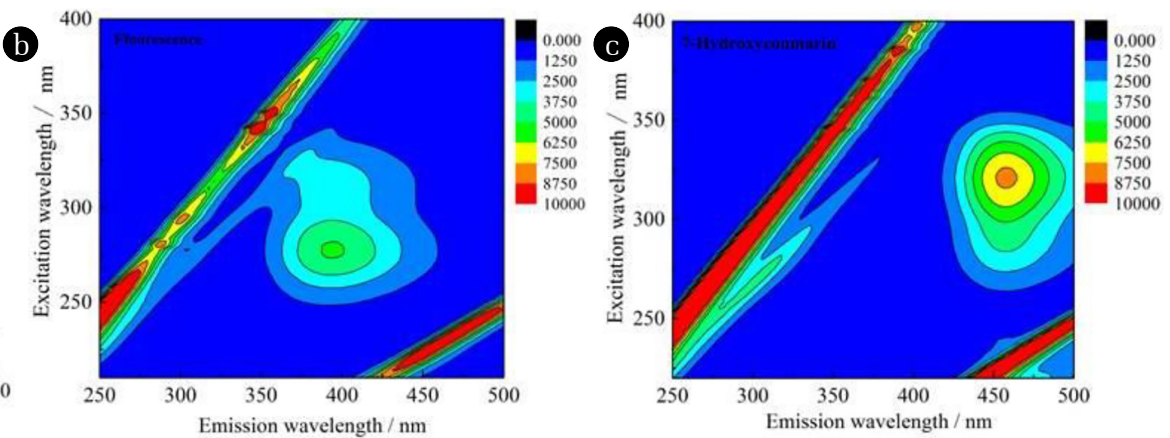

(b) Fluorescence spectroscopy of coumarin and (c) Fluorescence spectroscopy of 
Agilent USA). Thermostatic waterbath oscillator (SHA-C, Jintan Yichen Instrument Manufacturing Co., Ltd.) was used to control the reaction temperature. High speed centrifuge (TGL20M-II, Jintan Chengxi Chunlan Experimental Instrument Factory) was used in sample centrifugation.

\section{Results and Discussion}

\subsection{Catalyst Screening}

Fig. 2(a) and (b) is the standard curve of qunioline and $\mathrm{H}_{2} \mathrm{O}_{2}$, respectively. Fig. 2(c) is the effects of transition metal compounds on quinoline removal by Fenton-like system. As shown in Fig. 2(c), negligible difference was observed in the terms of the catalytic oxidation and degradation effects of copper sulfate, copper nitrate and copper chloride on quinoline. The removals were all above 95\% upon 65 min reaction, and more than $99 \% \mathrm{H}_{2} \mathrm{O}_{2}$ was consumed. However, the catalytic oxidation and degradation effect of copper acetate on quinoline was poor because of the only $82.9 \%$ removal. In addition, the catalytic oxidation and degradation performance of ferrous sulfate, ferric sulfate, cobalt sulfate and manganese sulfate were investigated, which indicated that manganese sulfate exhibited almost no catalytic oxidation and degradation ability to quinoline, the catalytic oxidation and degradation performance of cobalt sulfate was $30 \%$ lower than that of the above three copper compounds. Ferrous sulfate and ferric sulfate have certain ability of catalytic oxidation and degradation, but the water quality was muddy after the reaction, and the water quality after centrifugation was yellow, which was improved after $72 \mathrm{~h}$ precipitation. The results indicated that the three copper compounds (copper sulphate, nitric acid copper and copper chloride), with active component $\mathrm{Cu}^{2+}$, exhibited a higher catalytic oxidation degradation ability to quinoline, because chloride ion may have secondary pollution to water quality, and nitrate ion has a certain oxidation ability under acid condition, copper sulfate catalyst was selected to evaluate the ability of Fenton-like approach to the catalytic oxidation degradation.

\subsection{Effect of Catalyst Dosage}

The contribution of the respective catalyst adsorption, the volatilization of quinoline and the oxidation of separate $\mathrm{H}_{2} \mathrm{O}_{2}$ to the removal of quinoline wastewater was investigated before the study, and the results were $8.6,8.9$ and $8.5 \%$, respectively after $2 \mathrm{~h}$ reaction. As shown in Fig. 2(d), more than 95\% removal of three copper compounds to quinoline was achieved within $65 \mathrm{~min}$, which indicated that the synergistic effect of catalyst and hydrogen peroxide was the key to the degradation of Fenton-like method to wastewater.
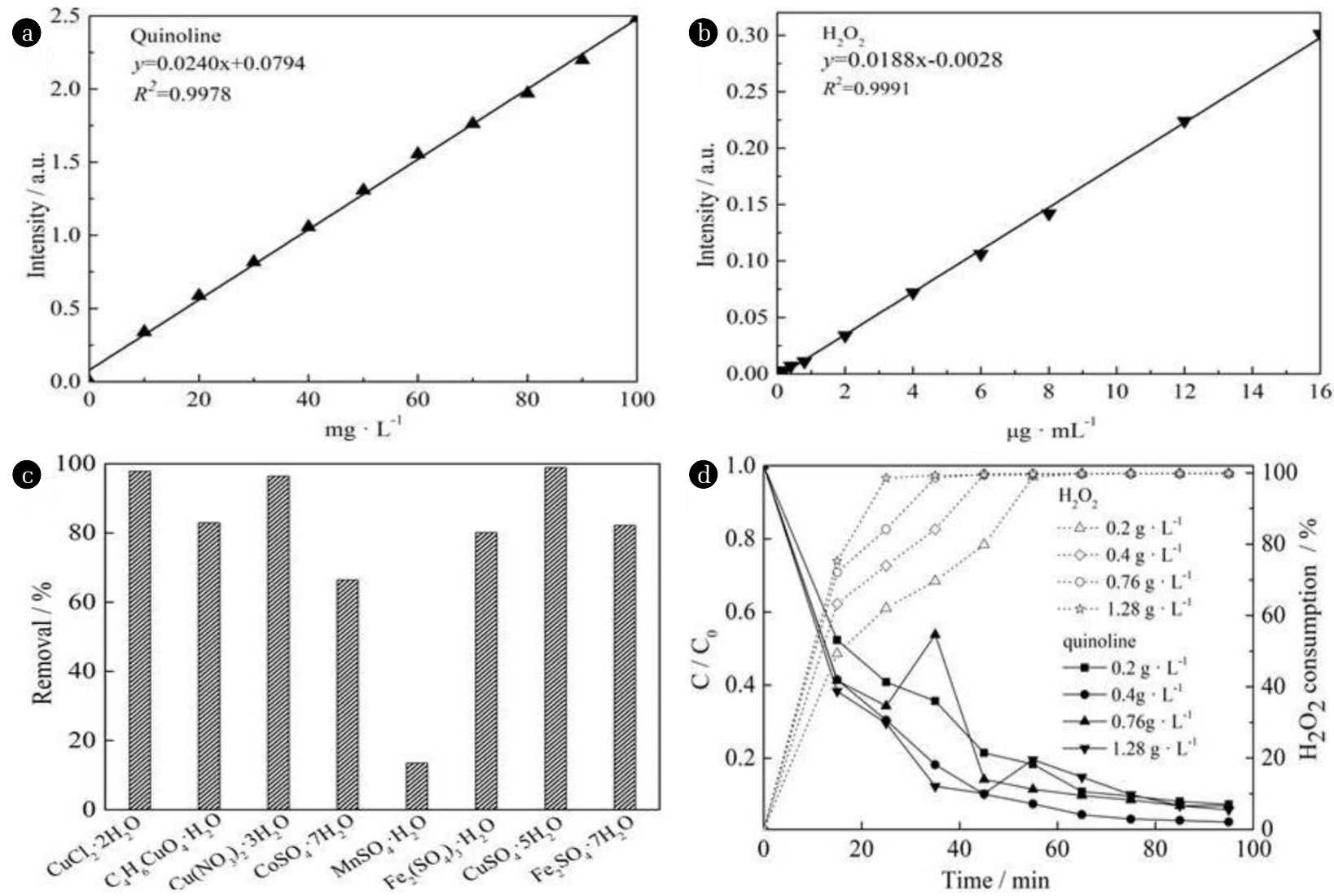

Fig. 2. Standard curves of (a) quinoline and (b) $\mathrm{H}_{2} \mathrm{O}_{2}$, (c) Effects of transition metal compounds on quinoline degradation by Fenton-like with catalyst $=1 \mathrm{~g} \cdot \mathrm{L}^{-1}, \mathrm{H}_{2} \mathrm{O}_{2}=196 \mathrm{mmol} \cdot \mathrm{L}^{-1}$, quinolone $=100 \mathrm{mg} \cdot \mathrm{L}^{-1}, t=65 \mathrm{~min}$, and $T=75^{\circ} \mathrm{C}$, and (d) Effect of catalyst dosage on quinoline degradation by Fenton-like with $\mathrm{H}_{2} \mathrm{O}_{2}=196 \mathrm{mmol} \cdot \mathrm{L}^{-1}$, quinolone $=100 \mathrm{mg} \cdot \mathrm{L}^{-1}, \mathrm{pH}=7.3$ and $T=75^{\circ} \mathrm{C}$. 
According to Fig. 2(d), the removal of quinoline showed much increment from $94.7 \%$ to $96.1 \%$ when the dosage of catalyst increased from $0.2 \mathrm{~g} \cdot \mathrm{L}^{-1}$ to $1.28 \mathrm{~g} \cdot \mathrm{L}^{-1}$ within the first $5 \mathrm{~min}$ of the reaction. However, the removals were all above $98.5 \%$ upon 65 min reaction, which demonstrated negligible little difference, indicating that the catalyst dosage exhibited less effect on the catalytic oxidation and degradation performance of quinoline along with the prolonged time. According to the highest removal of quinoline with $0.4 \mathrm{~g} \cdot \mathrm{L}^{-1}$ catalytic dosage in Fig. 2(d), 99.5\% and 99.7\% removals of quinoline were achieved after reaction of 65 and $95 \mathrm{~min}$, respectively, and the removals of TOC were $87.2 \%$ and $88.7 \%$, respectively. During the catalytic oxidation and degradation process of quinoline, the removal exhibited a remarkable reduction when $0.2 \mathrm{~g} \mathrm{~L}^{-1}$ catalyst dosage was applied upon 55 min reaction. At this time, the color of the solution became dark yellow which were not observed under the same condition when other catalyst dosages were used, indicating that the strong oxidizing $\bullet \mathrm{OH}$ concentration wasn't enough to accelerate oxidization and degradation of intermediate products under a lower catalyst dosage.

According to Fig. 2(d), in the early reaction time, the consumption of $\mathrm{H}_{2} \mathrm{O}_{2}$ was greatly affected by the catalyst dosage. After reacting for $15 \mathrm{~min}$, the consumption rate of $\mathrm{H}_{2} \mathrm{O}_{2}$ increased from $49.4 \%$ to $75.3 \%$ along with the increment of the catalyst dosage. However, after reacting for $55 \mathrm{~min}$, all of them reached more than $98.9 \%$, which was slightly affected by the catalyst dosage. As shown in Fig. 2(d), within $15 \mathrm{~min}$, more than $94.7 \%$ of the removal of quinoline could be achieved, which could be attributed to the low mass transfer resistance between $\mathrm{Cu}^{2+}$ and $\mathrm{H}_{2} \mathrm{O}_{2}$ under the Fenton-like reaction system, both could contact quickly and efficiently, leading to the accelerated transfer from $\mathrm{H}_{2} \mathrm{O}_{2}$ to strong oxidized $\bullet \mathrm{OH}$, enough strong oxidizing $\bullet \mathrm{OH}$ could be produced in a short period of time which have an oxidizing reaction with quinoline quickly.

The removal of quinoline exhibited the best when the catalyst dosage was $0.4 \mathrm{~g} \cdot \mathrm{L}^{-1}$, which can be attributed to the equilibrium between the generation and disappear of $\cdot \mathrm{OH}$ in the reaction system under the condition of the proper catalyst dosage. After the catalyst dosage continued to increase, excessive $\cdot \mathrm{OH}$ might be produced. But they haven't had enough time to participate in the organic oxidation reaction while part of them had a self-consumption reaction. On the other hand, the reaction of excessive $\bullet \mathrm{OH}$ and $\mathrm{H}_{2} \mathrm{O}_{2}$ resulted in the generation of $\mathrm{HOO}$. with a relatively poor oxidation capacity, and they may also reduce the catalytic capacity of the system.

\subsection{Effect of $\mathrm{H}_{2} \mathrm{O}_{2}$ Dosage}

The theoretical demand equation of $\mathrm{H}_{2} \mathrm{O}_{2}$ was $\mathrm{C}_{9} \mathrm{H}_{7} \mathrm{~N}+$ $23.5 \mathrm{H}_{2} \mathrm{O}_{2} 9 \mathrm{CO}_{2}+27 \mathrm{H}_{2} \mathrm{O}+\mathrm{NO}_{2}$, where $196 \mathrm{mmol} \cdot \mathrm{L}^{-1}$ was 10.7 times of the theoretical demand of $\mathrm{H}_{2} \mathrm{O}_{2}$. As shown in Fig. 3(a), $\mathrm{H}_{2} \mathrm{O}_{2}$ dosage didn't show a great influence on the removal of quinoline, the difference in the removal was about $2 \%$ after $45 \mathrm{~min}$ of reaction. Relatively speaking, when the amount of $\mathrm{H}_{2} \mathrm{O}_{2}$ dosage was $196 \mathrm{mmol} \cdot \mathrm{L}^{-1}$, the effect was slightly better. The removal of quinoline reached $95.8 \%$ after reacting for $15 \mathrm{~min}$, and 99.5\% after reacting for $65 \mathrm{~min}$. This result indicated that a small amount of $\mathrm{H}_{2} \mathrm{O}_{2}$ showed a relatively strong catalytic oxidation and degradation ability under Fenton-like reaction system, which fully showed its superiority. When the dosage of $\mathrm{H}_{2} \mathrm{O}_{2}$ was $313 \mathrm{mmol} \cdot \mathrm{L}^{-1}$ and $470 \mathrm{mmol} \cdot \mathrm{L}^{-1}$, obvious pale yellow intermediate products were generated at $35 \mathrm{~min}$ and $25 \mathrm{~min}$, respectively (as shown in Fig. 3(b)) and the color gradually disappeared after continuing reacting for a certain period of time.

\subsection{Effect of Reaction Temperature}

As shown in Fig. 4, after reacting for $15 \mathrm{~min}$, when the reaction temperature increased from $55^{\circ} \mathrm{C}$ to $85^{\circ} \mathrm{C}$, the removal of quinoline increased from $67.5 \%$ to $97.7 \%$, and the consumption of $\mathrm{H}_{2} \mathrm{O}_{2}$ showed increment from $12.9 \%$ to $82.6 \%$. That indicating that the reaction temperature had a great influence on the degradation effect of quinoline under the Fenton-like reaction system. When the reaction temperature was higher than $55^{\circ} \mathrm{C}$, such as $65^{\circ} \mathrm{C}, 75^{\circ} \mathrm{C}$ and $85^{\circ} \mathrm{C}$, no big difference of the removal of quinoline can be observed. The removal of quinoline increased by about $2 \%$ when the reaction temperature increased by every $10^{\circ} \mathrm{C}$. However, the consumption of $\mathrm{H}_{2} \mathrm{O}_{2}$ still changes greatly accompanying with varied temperature. The consumption of $\mathrm{H}_{2} \mathrm{O}_{2}$ was $68.9 \%$ and $99.6 \%$, respectively under $65^{\circ} \mathrm{C}$ and $75^{\circ} \mathrm{C}$ upon 45 min reaction with a difference of $30.7 \%$, while there was almost no difference under the condition of respective $75^{\circ} \mathrm{C}$ and $85^{\circ} \mathrm{C}$. So $75^{\circ} \mathrm{C}$ was a better reaction temperature. As shown in Fig. 4, both the removal of quinoline and the consumption of $\mathrm{H}_{2} \mathrm{O}_{2}$ increased along with the increment of reaction
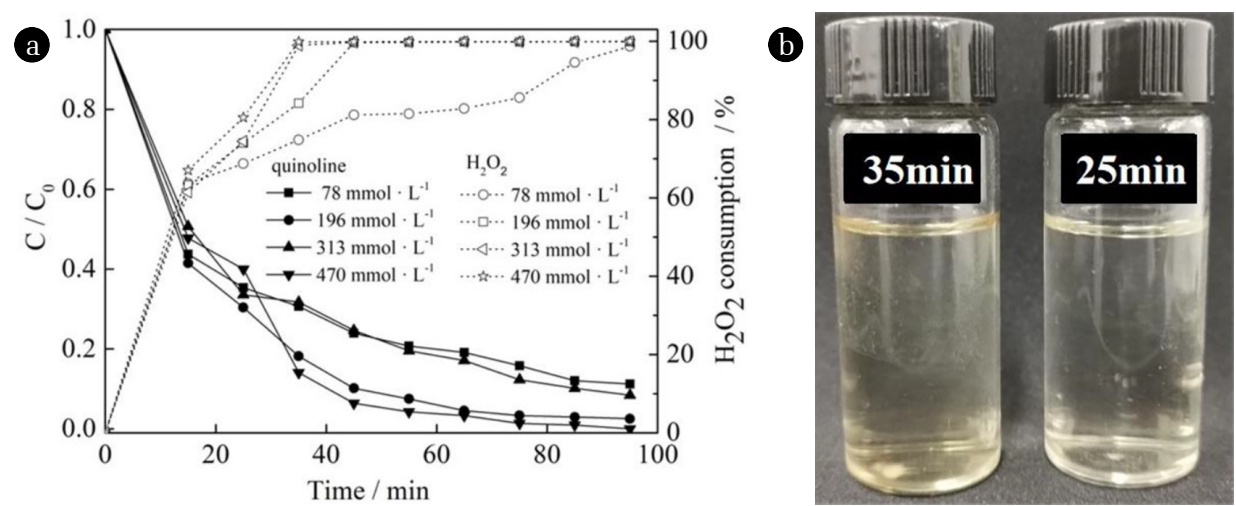

Fig. 3. (a) Effect of $\mathrm{H}_{2} \mathrm{O}_{2}$ dosage on quinoline degradation by Fenton-like with catalyst $=0.4 \mathrm{~g} \cdot \mathrm{L}^{-1}$, quinolone $=100 \mathrm{mg} \cdot \mathrm{L}^{-1}$, $\mathrm{pH}=7.3$ and $T=75^{\circ} \mathrm{C}$, (b) The digital image of the solution collected at 35 and $25 \mathrm{~min}$, respectively, during the reaction. 


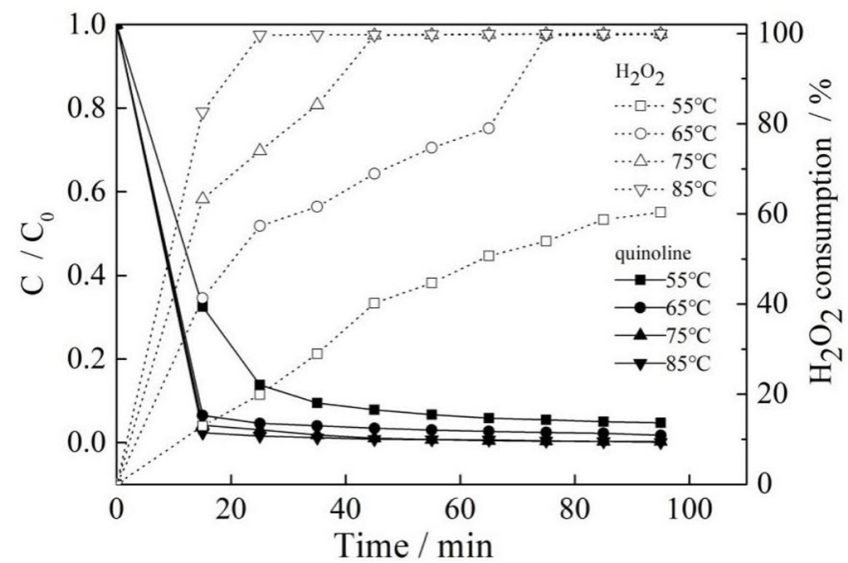

Fig. 4. Effect of reaction temperatures on quinoline degradation by Fenton-like with catalyst $=0.4 \mathrm{~g} \cdot \mathrm{L}^{-1}$, quinolone $=100 \mathrm{mg} \cdot \mathrm{L}^{-1}$, $\mathrm{H}_{2} \mathrm{O}_{2}=196 \mathrm{mmol} \cdot \mathrm{L}^{-1}$ and $\mathrm{pH}=7.3$

temperature. This means that it is difficult and not efficient for quinoline Fenton-like reaction under a lower reaction temperature, which could be attributed to the fact that it was not beneficial for the activation of $\mathrm{H}_{2} \mathrm{O}_{2}$ molecules to generate strong oxidizing - $\mathrm{OH}$ species and the activation of quinoline molecules at low reaction temperature. With the increase of the reaction temperature, the removal of quinoline increased significantly, but the curve of quinoline removal tended to be flat after exceeding $65^{\circ} \mathrm{C}$, which indicated that there was not remarkable effect on the removal of quinoline along with the prolonged reaction time. The main reason would be that equilibrium of reaction for a certain time was achieved. Then, most of quinoline had been oxidized and the left was less contacting with $\bullet \mathrm{OH}$.

\subsection{Effect of Initial Concentration of Quinoline}

According to Fig. 5, the removal of quinoline decreased from $97.8 \%$ to $96.3 \%$ when the concentration of quinoline increased significantly from $7.2 \mathrm{mg} \cdot \mathrm{L}^{-1}$ to $227.6 \mathrm{mg} \cdot \mathrm{L}^{-1}$ upon $15 \mathrm{~min}$ reaction, and the removal of quinoline reduced from $100 \%$ to $99.5 \%$ upon

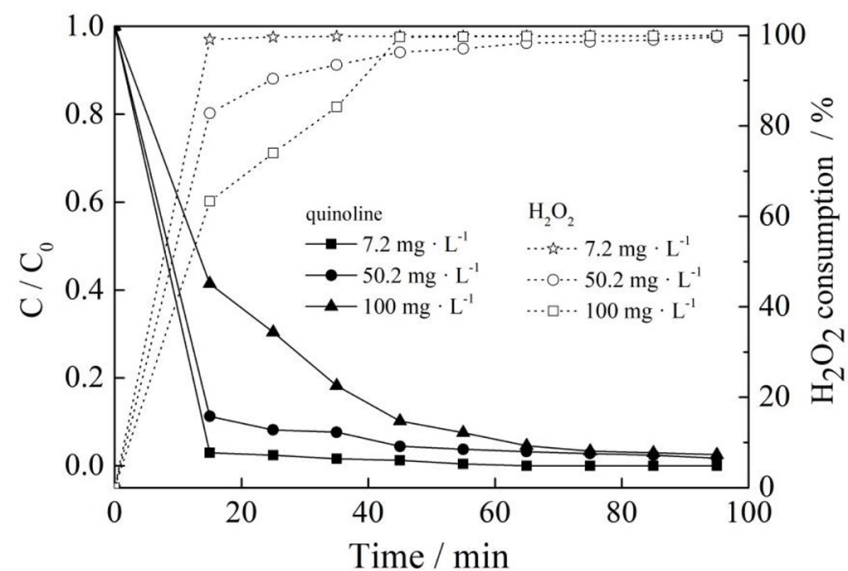

Fig. 5. Effect of initial concentrations on quinoline degradation by Fenton-like with catalyst $=0.4 \mathrm{~g} \cdot \mathrm{L}^{-1}, \mathrm{H}_{2} \mathrm{O}_{2}=196 \mathrm{mmol} \cdot \mathrm{L}^{-1}$, $\mathrm{pH}=7.3$ and $T=75^{\circ} \mathrm{C}$.
$65 \mathrm{~min}$ reaction. The results demonstrated that no obvious difference for the removal of quinoline was achieved in the early stage or late stage. It could be noted that the change of quinoline concentration had a little influence on its removal in the range of quinoline concentration discussed above. However, as seen from Fig. 5, the $\mathrm{H}_{2} \mathrm{O}_{2}$ consumption decreased with the increase of the quinoline concentration. The concentration had a greater influence within $45 \mathrm{~min}$. After the time, the consumption curve did not change significantly, which exceeded $97 \%$ after 55 min. The main reason for the decrease may be attributed to the increase of quinoline, which produced the intermediate products or bubbles forming a steric hindrance effect on preventing the full contact of $\mathrm{Cu}^{2+}$ from $\mathrm{H}_{2} \mathrm{O}_{2}$, thus leading to a slow decomposition of $\mathrm{H}_{2} \mathrm{O}_{2}$.

\subsection{Effect of Initial $\mathrm{pH}$}

According to Fig. 6, when the $\mathrm{pH}$ was between 3.8 and 8.8, the removal of quinoline in Fenton-like reaction system was over 94.0\%, it became higher than $99.0 \%$ upon 55 min reaction time. The results indicated that the $\mathrm{pH}$ exhibited almost no influence on the catalytic oxidation and degradation of quinoline within the researched $\mathrm{pH}$ range. As shown in Fig. 6, the consumption of $\mathrm{H}_{2} \mathrm{O}_{2}$ was greatly affected by the $\mathrm{pH}$ when the $\mathrm{pH}$ was in the range of 4.6 to 8.8. The consumption of $\mathrm{H}_{2} \mathrm{O}_{2}$ could be up to $99.6 \%$ when the $\mathrm{pH}$ was 5.8 upon 15 min reaction time. After that, the consumption curve tended to be flat, which might be ascribed to the complete consumption of $\mathrm{H}_{2} \mathrm{O}_{2}$. The consumptions of $\mathrm{H}_{2} \mathrm{O}_{2}$ were determined to be $62.6,63.3$ and $67.1 \%$ upon 15 min reaction time under the acidic condition with a $\mathrm{pH}$ of 3.8 and the alkaline condition with a pH of 7.3 and 8.8, respectively, which indicated that the decomposition of $\mathrm{H}_{2} \mathrm{O}_{2}$ was affected almost in the same way under weak acidic and alkaline conditions in a relatively short period of reaction time. The consumption of $\mathrm{H}_{2} \mathrm{O}_{2}$ under the three $\mathrm{pH}$ conditions tended to be consistent after $65 \mathrm{~min}$ reaction time, reaching about $99 \%$, this demonstrated that the environment of reaction might be almost same gradually after some intermediate products were generated and disappeared as the reaction continued. It can be found that the $\mathrm{pH}$ had a little influence on the final degradation result when the initial $\mathrm{pH}$ was between 3.8 and 8.8 after a long

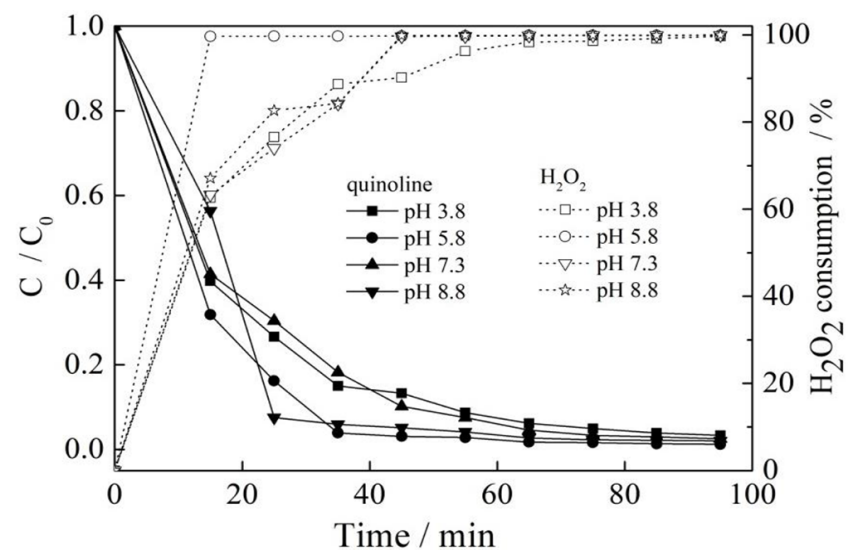

Fig. 6. Effect of $\mathrm{pH}$ on quinoline degradation by Fenton-like with catalyst $=0.4 \mathrm{~g} \cdot \mathrm{L}^{-1}, \mathrm{H}_{2} \mathrm{O}_{2}=196 \mathrm{mmol} \cdot \mathrm{L}^{-1}$, quinolone $=100 \mathrm{mg} \cdot \mathrm{L}^{-1}$ and $T=75^{\circ} \mathrm{C}$. 
reaction time. According to the removal effect of quinoline by $\mathrm{pH}$, as Fenton method generally reacts under the condition of $\mathrm{pH}$ 2-4, the Fenton-like method using copper sulfate as catalyst had wider $\mathrm{pH}$ adaptability and obvious advantages compared with Fenton method.

\subsection{Hydroxyl Radical and pH Concentration Changes}

The changes of $\mathrm{pH}$ and $\bullet \mathrm{OH}$ concentration in the reaction process can provide basis for further investigation of degradation mechanism and pathway. In addition, with the progress of the reaction, whether the $\mathrm{pH}$ of the reaction system will exceed the $\mathrm{pH}$ adaptation range of the catalyst needs further analysis. Whether the $\bullet \mathrm{OH}$ participate in the reaction is investigated by the change of the concentration of hydroxyl radicals. Fig. 7(a) is the standard curve of 7-hydroxycoumarin. Fig. 7 (b) is the change of $\mathrm{pH}$ and $\bullet \mathrm{OH}$ concentration during the reaction. As shown in Fig. 7(b), in the quinoline Fenton-like reaction system, the $\mathrm{pH}$ of the system first rose and then descended. Meanwhile the precipitation was observed during the reaction process that implies $\mathrm{Cu}(\mathrm{OH})_{2}$ precipitation was obtained under alkaline environment. Reducing $\mathrm{Cu}^{2+}$ active components and leading to decreased strong oxidizing $\bullet \mathrm{OH}$ made them not enough to fully oxidize intermediates in a short time. Then the intermediates stayed for a longer time, and some acid intermediates were produced, leading to the decrease of the $\mathrm{pH}$ of the system. Fig. 7(b) demonstrated that the concentration of $\bullet \mathrm{OH}$ gradu- ally decreased along with prolonged reaction time in Fenton-like reaction system, implying that most $\bullet \mathrm{OH}$ were participated in the reaction.

\subsection{Degradation Pathways}

The GC-MS analyses revealed the quinoline, p-xylene, aniline $\mathrm{N}$-methyl, benzenamine 3-methyl-, carbamic acid phenyl ester-, styrene, benzaldehyde 4-(dimethylamino)- might form as intermediates. Their common characteristic is the disappearance of nitrogen-containing rings, which demonstrated the nitrogen-ring was firstly attacked by $\bullet \mathrm{OH}$ during the reaction, opening the nitrogen-ring first and then further attacking the benzene ring. This is closely related to the high density of $\mathrm{N}$-ring electron cloud in the quinoline structure, and the electrophilic addition reaction easily happened. The possible degradation pathways and scheme of quinoline are shown in Fig. 8(a) and (b). In conclusion, $\cdot \mathrm{OH}$ plays a great role in the degradation of quinolone, the reaction between $\mathrm{Cu}^{2+} / \mathrm{Cu}^{+}$takes place in the presence of $\mathrm{H}_{2} \mathrm{O}_{2}$ forming $\cdot \mathrm{OH}$ and $\mathrm{HO}_{2}$, the mechanism is illustrated as follows:

$$
\begin{gathered}
\mathrm{Cu}^{2+}+\mathrm{H}_{2} \mathrm{O}_{2} \rightarrow \mathrm{CuOOH}^{+}+\mathrm{H}^{+} \\
\mathrm{CuOOH}^{+} \rightarrow \mathrm{Cu}^{+}+\mathrm{H}+\mathrm{O}_{2}^{-} \\
\mathrm{Cu}^{+}+\mathrm{H}_{2} \mathrm{O}_{2} \rightarrow \mathrm{Cu}^{2+}+\mathrm{OH}+\mathrm{OH}^{-}
\end{gathered}
$$
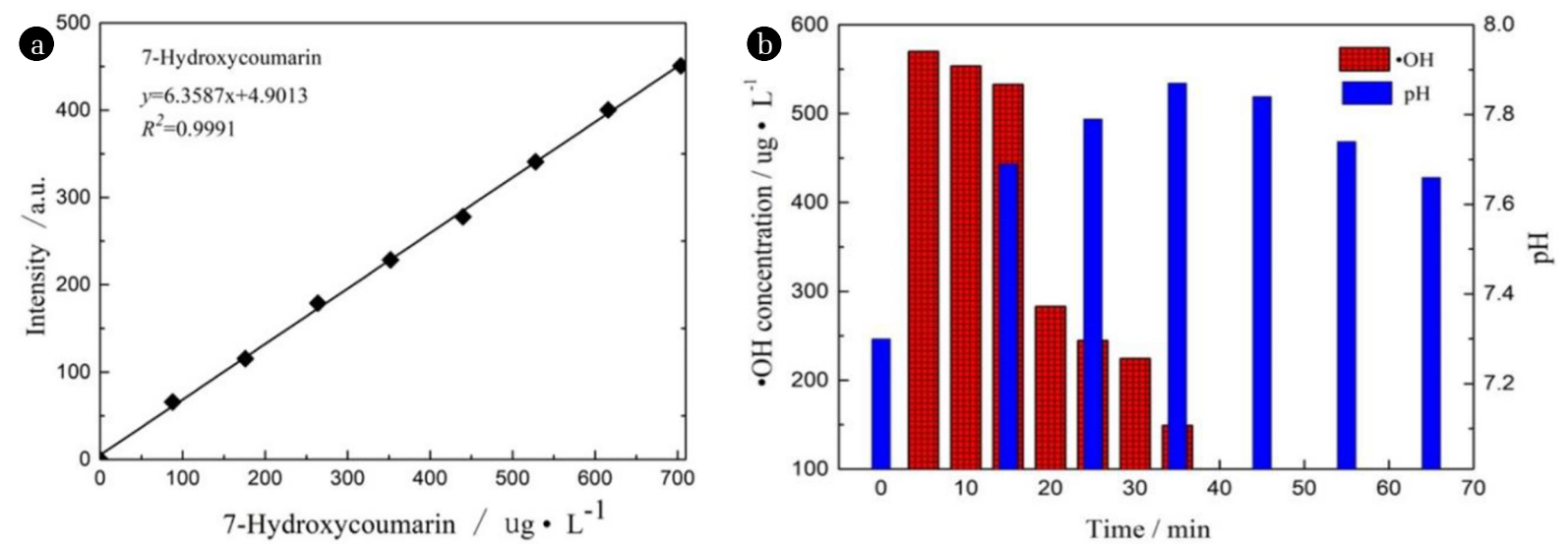

Fig. 7. (a) Standard curves of 7-Hydroxycoumarin and (b) The change of $\mathrm{pH}$ and $\cdot \mathrm{OH}$ concentration in Fenton-like system with catalyst $=1 \mathrm{~g} \cdot \mathrm{L}^{-1}$, $\mathrm{H}_{2} \mathrm{O}_{2}=196 \mathrm{mmol} \cdot \mathrm{L}^{-1}$, quinolone $=100 \mathrm{mg} \cdot \mathrm{L}^{-1}$ and $T=75^{\circ} \mathrm{C}$.
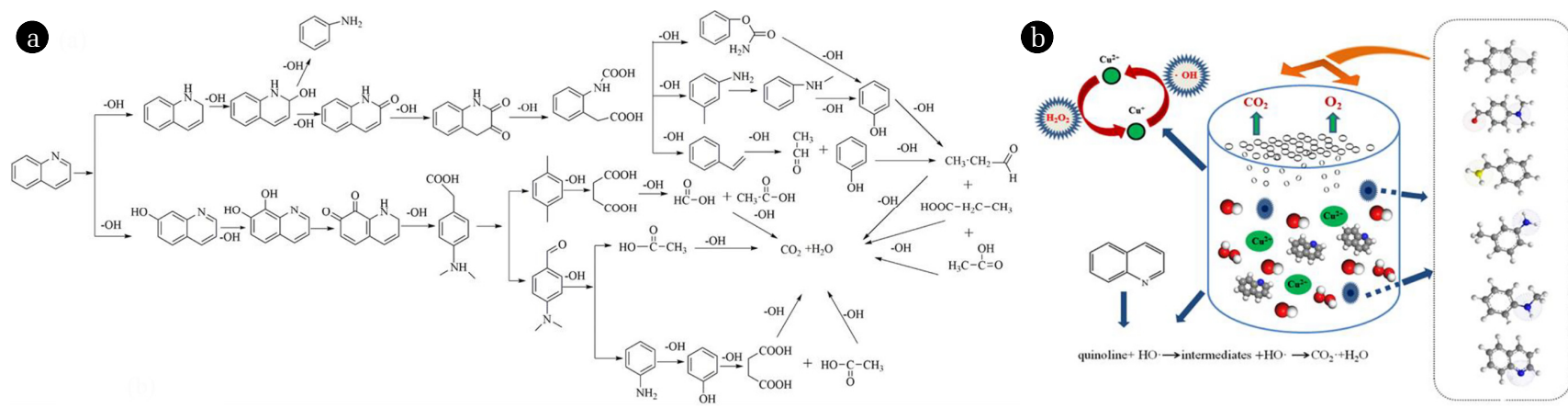

Fig. 8. (a) Probable degradation pathway of quinoline and (b) scheme of probable catalytic mechanism of quinolone. 


$$
\begin{gathered}
\mathrm{Cu}^{2+}+\mathrm{HO}_{2} \bullet \rightarrow \mathrm{Cu}^{+}+\mathrm{H}^{+}+\mathrm{O}_{2} \\
\mathrm{H}_{2} \mathrm{O}_{2}+\cdot \mathrm{OH} \rightarrow \mathrm{HO}_{2} \bullet+\mathrm{H}_{2} \mathrm{O} \\
\text { quinoline }+\mathrm{HO} \bullet \rightarrow \mathrm{CO}_{2}+\mathrm{H}_{2} \mathrm{O}+\text { intermediates }
\end{gathered}
$$

\section{Conclusions}

In earlier stage, increasing catalyst dosage was conducive to the increasing of reaction speed but in the final stage, it had no significant influence. $\mathrm{H}_{2} \mathrm{O}_{2}$ influence in degradation was not large, while the degradation increased with the increase of reaction temperature. Within the concentration range of this experiment, the change of quinoline concentration has little effect on degradation. The $\mathrm{pH}$ of the solution increased to the maximum and then decreased during the reaction. As a result, the removal efficiency of quinoline and TOC were $99.5 \%$ and $87.2 \%$, respectively, when $0.4 \mathrm{~g} \cdot \mathrm{L}^{-1}$ catalyst, $196 \mathrm{mmol} \cdot \mathrm{L}^{-1} \mathrm{H}_{2} \mathrm{O}_{2}$ and $100 \mathrm{mg} \cdot \mathrm{L}^{-1}$ quinoline was applied under $75^{\circ} \mathrm{C}$ reaction within $65 \mathrm{~min}$. The Fenton-like method with copper sulfate as a catalyst took an obvious advantage over Fenton method for catalytic oxidative degradation of quinoline, which was able to react under raw solution $\mathrm{pH}$ 3.8-8.8. The degradation mechanisms showed that copper sulfate could generate $\bullet \mathrm{OH}$ radicals through catalyzing $\mathrm{H}_{2} \mathrm{O}_{2}$ by $\mathrm{Cu}^{2+}$, which first attacked nitrogen ring, followed by benzene ring.

\section{Acknowledgments}

This work was financially supported by grants from the National Natural Science Foundation of China (Grant No. 22178036 and No. 22008216), Key Special Project of Strategic International Scientific and Technological Innovation Cooperation (2016YF E0205600), Projects of Scientific and Technological Research Program of Chongqing Municipal Education Commission (KJQN201900823， KJZD-K201800801，KJQN201800813， and KJQN202100817), and Natural Science Foundation of Chongqing, China (cstc2020 jcyj-bshX0061), and Projects of Opening Platform and Startup Foundation from Chongqing Technology and Business University (KFJJ2018062, 1956004).

\section{References}

1. Wang Q, Yang ZM. Industrial water pollution, water environment treatment, and health risks in China. Environ. Pollut. 2016;218:358-365.

2. Oh W, Lok LW, Veksha A, Giannis A, Lim TT. Enhanced photocatalytic degradation of bisphenol A with Ag-decorated S-doped g- $\mathrm{C}_{3} \mathrm{~N}_{4}$ under solar irradiation: Performance and mechanistic studies. Chem. Eng. J. 2018;333:739-749.

3. Zhang YT, Wang YK, Lu QY, et al. The role of ultrasound-treated sludge for accelerating quinoline mono-oxygenation. J. Environ. Manage. 2019;233:561-566.

4. Zhu H, Ma WC, Han HJ, Han YX, Ma WW. Catalytic ozonation of quinoline using nano-MgO: Efficacy, pathways, mechanisms and its application to real biologically pretreated coal gasification wastewater. Chem. Eng. J. 2017;327(1):91-99.

5. Chu LB, Yu SQ, Wang J. Degradation of pyridine and quinoline in aqueous solution by gamma radiation. Radiation. Radiat. Phys. Chem. 2018;144:322-328.

6. Chen AL, Zhang LP, Chang MF, Ge YJ, Wang KJ. Degradation of quinoline from biotreated effluent with ozone-based advanced oxidation processes. Chin. J. Environ. Eng. 2015;9(12): 5795-5800.

7. Chen QQ, Xu LZJ, Zhang ZZ, et al. Insight into the short-and long-term effects of quinoline on aammox granules: Inhibition and acclimatization. Sci. Total. Environ. 2019;651:1294-1301.

8. Pachupate NJ, Vaidya PD. Catalytic wet oxidation of quinoline over Ru/C catalyst. J. Environ. Chem. Eng. 2018;6(1):883-889.

9. Mashhadi N, Taylor KE, Biswas N, Meister P, Gauld JW. Oligomerization of 3-substituted quinolines by catalytic activity of soybean peroxidase as a wastewater treatment. Product formation and computational studies. Chem. Eng. J. 2019;364: 340-348.

10. Wang CR, Ma KK, Wu TT, Ye M, Tan P, Yan KC. Electrochemical mineralization pathway of quinoline by boron-doped diamond anodes. Chemosphere 2016;149:219-223.

11. Rameshraja D, Srivastava VC, Kushwaha JP, Mall ID. Quinoline adsorption onto granular activated carbon and bagasse fly ash. Chem. Eng. J. 2012;181-182:343-351.

12. De Oliveira Ferreira ME, Vaz BG, Borba CE, Alonso CG, Ostroski IC. Modified activated carbon as a promising adsorbent for quinoline removal. Microporous. Mesoporous. Mater. 2019;277: 208-216.

13. Li J, Li WY. Screening of a highly efficient quinoline degrading strain and its enhanced biotreatment on coking waste water. Environ. Sci. 2015;36(04):1385-1391.

14. Zhang YX, Dou MN, Zhu KX, Chai TY, Zhang YM, Xu WC. Bioaugmentation and characteristics of a quinoline-degrading strain Rhodococcus sp. China. Environ. Sci. 2017;37(06): 2340-2346.

15. Lu QY, Zhang CY, Wang WY, Yuan BY, Zhang YM, Rittmann BE. Bioavailable electron donors leached from leaves accelerate biodegradation of pyridine and quinolone. Sci. Total. Environ. 2019;654:473-479.

16. Hou SY, Liu YJ, Liu Y. Effect of Acclimation Conditions on the Quinoline Degradation Rat. Technol. Water. Treat. 2017;(04):66-69. (in Chinese)

17. Bello MM, Abdul Raman AA, Asghar A. A review on approaches for addressing the limitations of Fenton oxidation for recalcitrant wastewater treatment. Process. Saf. Environ. Prot. 2019;126: 119-140.

18. Pinto LD, Dos Santos LMF, Al-Duri B, Santos RC. Supercritical water oxidation of quinoline in a continuous plug flow reactor-part 1: effect of key operating parameters. J. Chem. Technol. Biotechnol. 2006;81(6):912-918.

19. Ren MM, Wang SZ, Yang CX, Xu HT, Guo Y, Roekaerts D. Supercritical water oxidation of quinoline with moderate preheat temperature and initial concentration. Fuel 2019;236: 1408-1414.

20. Stapleton DR, Konstantinou IK, Karakitsou A, Hela DG, Papadaki M. 2-Hydroxypyridine photolytic degradation by $254 \mathrm{~nm}$ UV 
irradiation at different conditions. Chemosphere 2009;77(8): 1099-1105.

21. Wu DY, Wang F, Tan YB, Li CL. Facile synthesis of NiS/CdS nanocomposites for photocatalytic degradation of quinoline under visible-light irradiation. RSC. Adv. 2016;6(77):73522-73526.

22. Fu J, Yu YG, Zhao YD, Wang Y. Simulated sunlight- heterogeneous Fenton degradation of quinoline in wasterwater. Environ. Chem. 2017;36(5):1072-1082.

23. Ma XJ, Bian LX, Ding JF, Wu YP, Xia HL, Li JH. Electrochemical oxidation of quinoline aqueous solution on $\beta-\mathrm{PbO}_{2}$ anode and the evolution of phytotoxicity on duckweed. Water Sci. Technol. 2017;75(8):1820-1829.

24. Thomsen AB, Laturnus F. The influence of different soil constituents on the reaction kinetics of wet oxidation of the creosote compound quinolone. J. Hazard. Mater. 2001;81(1-2):193-203.

25. Chen H, Lee JC, Zheng YY, Duan QN. A non-traditional energy transfer process in CWPO heterogeneous reaction for wastewater treatment. Chem. Eng. Res. Des. 2016;114:142-147.

26. Zhang B, You H, Wang F, Yang ZZ. Influence of nickel incorporation on the structure and catalytic behavior of Cu-cata- lyst for heterogeneous catalytic wet peroxide oxidation of quinoline under microwave irradiation. Catal. Commun. 2017;88: 56-59.

27. Han J, Zeng HY, Xu S, Chen CR, Liu XJ. Catalytic properties of CuMgAlO catalyst and degradation mechanism in CWPO of methyl orange. Appl. Catal. A. 2016;527:72-80.

28. Mei Y, Zeng JC, Sun MY, Ma JF, Komarneni S. A novel Fenton-like system of $\mathrm{Fe}_{2} \mathrm{O}_{3}$ and $\mathrm{NaHSO}_{3}$ for Orange II degradation. Sep. Purif. Technol. 2020;230:115866.

29. Leifeld V, Dos Santos TPM, Zelinski DW Igarashi-Mafra L. Ferrous ions reused as catalysts in Fenton-like reactions for remediation of agro-food industrial wastewater. J. Environ. Manage. 2018;222:284-292.

30. Yang XJ, Tian PF, Zhang CX, et al. Au/carbon as Fenton-like catalysts for the oxidative degradation of bisphenol A. Appl. Cata. B. 2013;134-135:145-152.

31. Czili H, Horváth A. Applicability of coumarin for detecting and measuring hydroxyl radicals generated by photoexcitation of $\mathrm{TiO}_{2}$ nanoparticles. Appl. Catal. B. 2008;81(3-4):295-302. 